\title{
Nanotheranostic Application of Fluorescent Protein-Gold Nanocluster Hybrid Materials: A Mini-review
}

\author{
Han Ding ${ }^{1,2,3 凶}{ }^{\circledR}$ Zhijun Chen ${ }^{2 \llbracket}$ \\ 1. Wenzhou Institute, University of Chinese Academy of Sciences, Wenzhou, Zhejiang, 325000, China. \\ 2. State Key Laboratory of Supramolecular Structure and Materials, College of Chemistry and Institute of Theoretical Chemistry, Jilin University, Changchun \\ 130012, China. \\ 3. Institute for translational medicine, Affiliated Hospital, Medical college of Qingdao University, Dengzhou Road 38, Qingdao 266021, China. \\ $\bowtie$ Corresponding authors: E-mail: zchen@jlu.edu.cn (ZJ. Chen); dinghan2011@163.com (H. Ding). \\ (C) The author(s). This is an open access article distributed under the terms of the Creative Commons Attribution License (https://creativecommons.org/licenses/by/4.0/). \\ See http://ivyspring.com/terms for full terms and conditions.
}

Received: 2021.01.11; Accepted: 2021.04.21; Published: 2021.05.17

\begin{abstract}
The gold nanoclusters (Au NCs) are a special kind of gold nanomaterial containing several gold atoms. Because of their small size and large surface area, Au NCs possess macroscopic quantum tunneling and dielectric domain effects. Furthermore, Au NCs fluorescent materials have longer luminous time and better photobleaching resistance compared with other fluorescent materials. The synthetic process of traditional Au NCs is complicated. Traditional Au NCs are prepared mainly by using polyamide amine type dendrites, and sixteen alkyl trimethylamine bromide or sulfhydryl small molecule as stabilizers. They are consequently synthesized by the reduction of strong reducing agents such as sodium borohydride. Notably, these materials are toxic and environmental-unfriendly. Therefore, there is an urgent need to develop more effective methods for synthesizing Au NCs via a green approach. On the other hand, the self-assembly of protein gold cluster-based materials, and their biomedical applications have become research hotspots in this field. We have been working on the synthesis, assembly and application of protein conjugated gold clusters for a long time. In this review, the synthesis and assembly of protein-gold nanoclusters and their usage in cell imaging and other medical research are discussed.
\end{abstract}

Key words: gold nanoclusters; synthetic method; ion detection; bioimaging; medical applications

\section{Introduction}

Gold nanoclusters (Au NCs), a special kind of particles, are usually composed of several to hundreds of gold atoms [1-3], with size approximately several nanometers, which are something between gold atoms and gold nanoparticles. Au NCs show some special properties: such as the surface, quantum size, volume, the red-light quantum tunneling, and the dielectric confinement effects. This phenomenon is mainly attributed to the increase of the local field strength of the Au NC surface and the internal field. The dielectric confinement of Au NCs may have an important effect on optical absorption, optical nonlinearity and photochemistry [4-8].

The $\mathrm{Au}$ NCs exhibit unique physical and chemical properties compared with the traditional inorganic light-emitting materials such as quantum dots (QDs) and organic fluorescent molecules. QDs frequently contain heavy metal elements, such as cadmium, lead, and mercury, which are harmful to the human body and the environment. In contrast, organic fluorescent materials have short fluorescence life and display photobleaching property, which hinders their applications in biomedical research. Au NCs contain various advantages such as low toxicity, good biocompatibility, stable luminescence, strong anti-bleaching capability and high stability. Therefore, they display great potential in the field of environmental detection, biomarker development, cell imaging and drug loading [8-24]. Different protectants can be used to synthesize Au NCs (Figure 
1), such as sulfhydryl small molecule [25], dendritic macromolecules, dksl [26] traditional polymers [27], biopolymer DNA [28], and proteins [29].

Among biomolecules, DNAs and proteins are popular ones used for the synthesis of nanoparticles. DNA has been used to synthesize silver nanoparticles and silver NCs. For instance, Zhou et al. synthesized eight gold Atom-Au NCs by using ultrasonic reactor and DNA etching [28]. Liu et al. successfully synthesized $\mathrm{Au}$ NCs under acidic conditions by using a single strain DNA as a protectant and two methylamine boranes as a reductant [30]. They verified that the luminescence position of the NCs was $725 \mathrm{~nm}$, and the luminescence property was stable.

Many efforts have been conducted on the synthesis of protein capped Au NCs. The sulfhydryl group of cysteine in the protein has a strong affinity with gold, so it serves as a good Au NC stabilizer. Proteins can be cross-linked with the Au NCs. However, $\mathrm{Au}$ NCs may locate inside the protein structure, and the protein still preserves its original structure and function [31]. It was proposed that under the strong alkaline condition, bovine serum albumin (BSA) could function as the protector and reductant. Xie et al. prepared Au NCs by using BSA [29]. They also studied the functional applications of protein-capped gold clusters [32]. Besides, many proteins such as lysozyme, pepsin, enoyl-ACP reductase and so on were used to synthesize Au NCs [33-35].

Wei et al. synthesized Au NCs by employing lysozyme as the stabilizer. They managed to diffract the structure of the Lysozyme-Au NCs. Lysozyme-Au NCs were used to study the interaction between protein and gold [36]. Liu et al. produced Insulin-Au NCs at low temperature $\left(4^{\circ} \mathrm{C}\right)$ [37]. Insulin-Au NCs retains the activity of insulin, which is an example of the original activity containing protein-NCs.

$\mathrm{Au}$ NCs synthesized by biomolecules are more biocompatible and harmless than other Au NCs and other materials.

On the basis of the traditional approach of protein-gold cluster synthesis, we used small molecules of mercapto and recombinant protein enoyl-ACP reductase to synthesize gold clusters. By analyzing the differences of gold clusters synthesized using different proteins and comparing their amino acid sequences, we put forward the idea of synthesizing gold clusters based upon protein, amino acid, and chloroauric acid. Therefore, the synthesis of various protein $\mathrm{Au}$ NCs hybrid self-assembled materials was tried with BSA and amino acids (e.g., glycine and histidine) in different conditions $[38,39]$. Several gold cluster hybrid materials with different luminescence properties were obtained. The synthesis mechanism of these materials was also elucidated. Based on the results of SDS-PAGE, protein crosslinking occurred in the process of gold cluster synthesis, and free radicals were detected in this process, which may be the cause of crosslinking. We proposed a mechanism of free radicals initiating gold cluster synthesis [39].

\section{Au NCs synthesized with different proteins}

In 2009, Xie et al. used BSA for the first time to synthesize Protein-Au NCs [29]. Thereafter, improved synthetic approaches involving different proteins have been developed to synthesize Protein-Au NCs (Figure 2) [40-51].

\section{Traditional approach for protein Au NCs synthesis}

BSA was frequently used in a traditional method for synthesizing $\mathrm{Au}$ NCs. Specifically, BSA and chloric acid were mixed at a certain molar ratio $(3: 40)$, and BSA was served as a protector and reducing agent to reduce the trivalent gold to zero value in strong alkaline and $37^{\circ} \mathrm{C}$ environment [29]. The $\mathrm{Au}$ NCs produced by this method usually contains about 25 gold atoms, with size about $1 \mathrm{~nm}$. The prepared $\mathrm{Au}$ NCs emitted red fluorescence $(640 \mathrm{~nm})$ when excited at $480 \mathrm{~nm}$, the fluorescence quantum yield of which was about $6 \%$.

\section{Synthesis of Protein-Au NCs by microwave method}

Researchers mixed BSA and chloroauric acid at a certain molar ratio (3:40), under strong alkaline followed by microwave treatment [52,53]. The $\mathrm{Au}$ NCs synthesized by this method contains about 16 gold atoms, the size of which is about $0.8 \mathrm{~nm}$. These AuNCs show red fluorescence $(604 \mathrm{~nm})$ with excitation at $365 \mathrm{~nm}$.

\section{Synthesis of heating protein Au NCs Hydrogel}

BSA and chloroauric acid were mixed at a certain molar ratio $(25: 162)$ under alkaline conditions. The reaction takes place at $50{ }^{\circ} \mathrm{C}$ for 3 hours. The protein was self-assembled to form a gel network structure, which can further reduce the chloroauric acid to form gold nanoclusters. The hydrogel type gold cluster material obtained by this method illuminates at 660 $\mathrm{nm}$ under the excitation of $470 \mathrm{~nm}$ [54]. Scanning electron microscopy (SEM) and transmission electron microscopy (TEM) showed that the whole material exhibited porous fiber structure, with gold embedded in the hydrogel. 


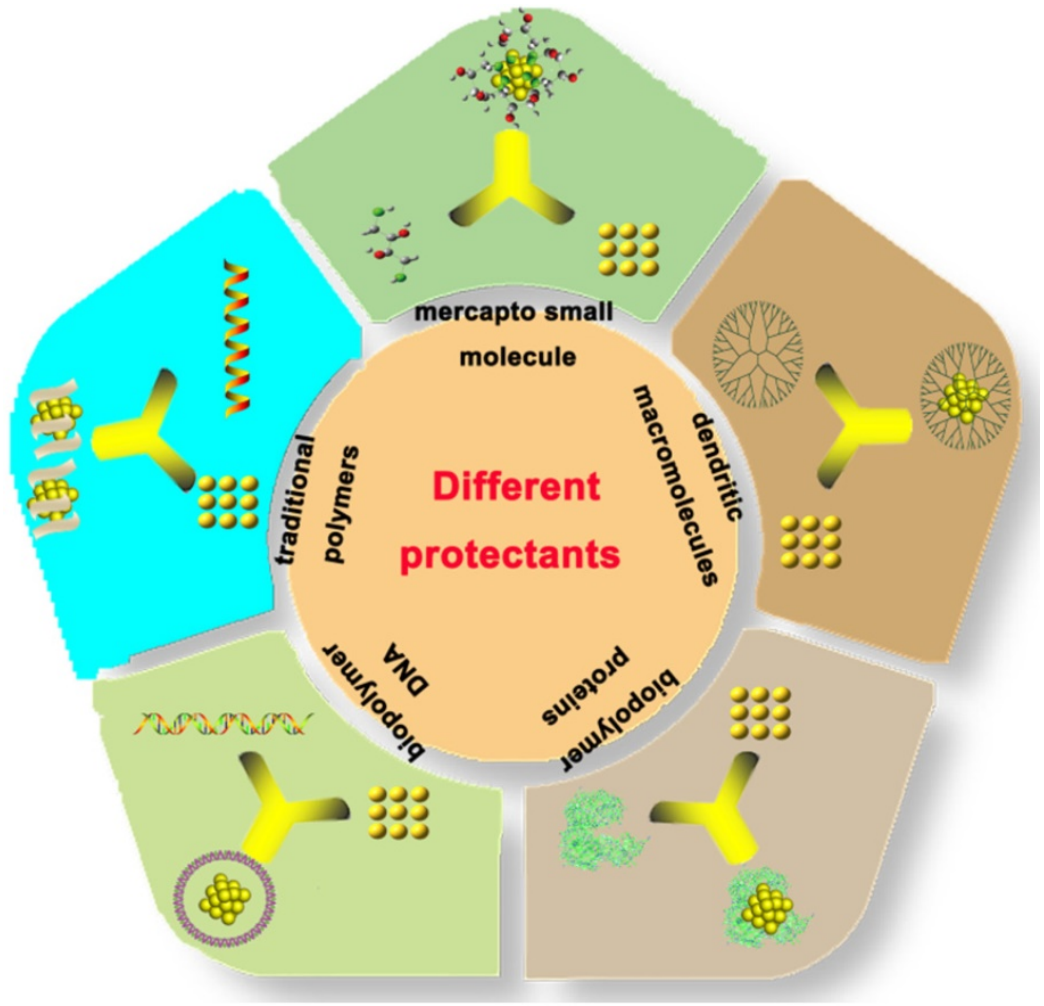

Figure 1. Different strategies for the synthesis of gold nanoclusters.

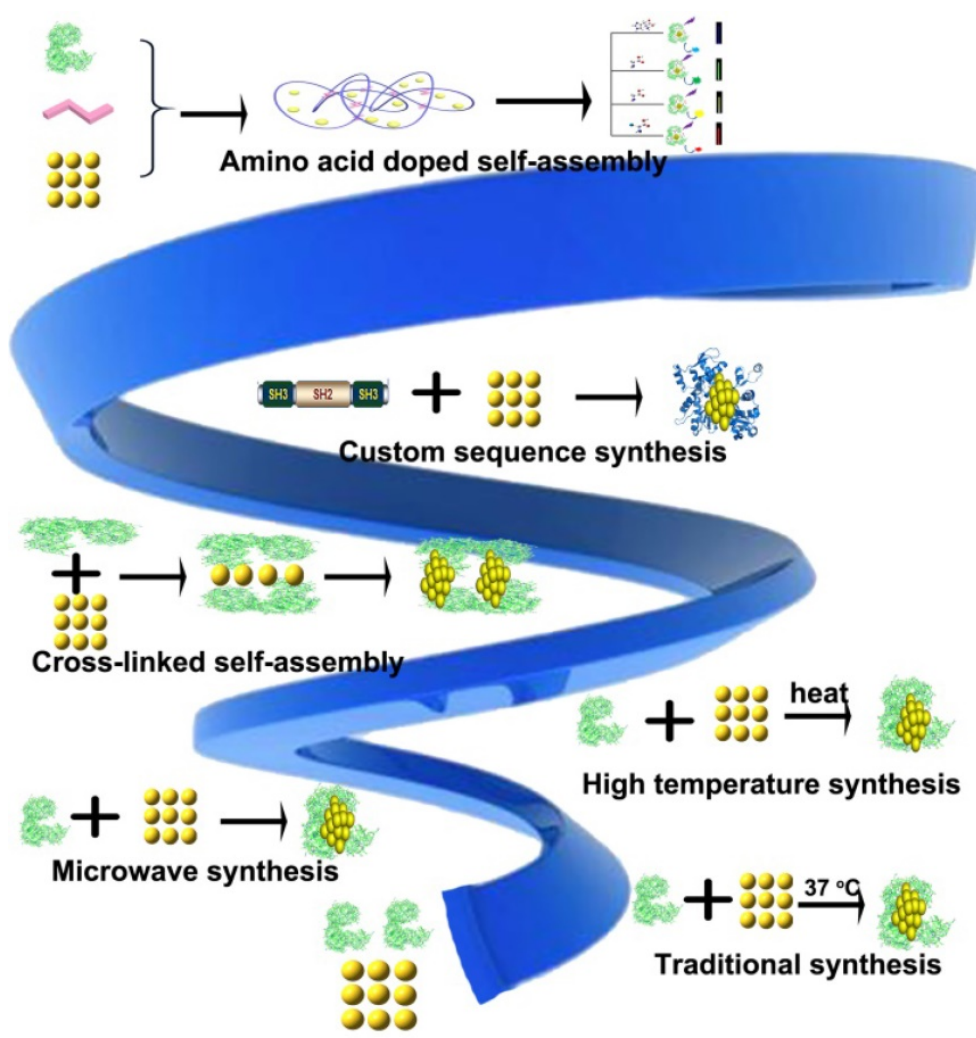

Figure 2. Schematic representation of different approaches for the synthesis of protein-gold nanoclusters.

\section{Synthesis of Protein-Au NCs by heating}

Researchers further improved the synthetic method. Detailedly, BSA was mixed with chloric acid at a certain molar ratio (3:40), in the strong alkaline and $97^{\circ} \mathrm{C}$. BSA was used as a protective as well as reducing agent to reduce the trivalent gold to zero valent gold; and the gold atoms were coated with BSA 
to form Au NCs. The size of Au NCs synthesized by this method is about $6.3 \mathrm{~nm}$, with excitation and emission at $375 \mathrm{~nm}$ and $625 \mathrm{~nm}$, respectively. Structural characterization showed that several residues of BSA such as tyrosine could be very active in forming radicals under alkali conditions during AuNCs synthesis. These active residues likely triggered radical-mediated cross-linking, which activated the formation of the rod-shaped material [55].

\section{Other proteins to synthesize protein Au NCs}

In addition to using BSA to synthesize protein clusters, researchers also used other proteins to synthesize Protein-Au NCs [55-66].

\section{Human serum albumin (HSA)-Au NCs}

HSA can be used as a protective agent and reducing agent to synthesize the Protein-Au NCs. HSA was mixed with chloroauric acid at a specific molar ratio (3:40), where HSA served as a protector and reducing agent under strong alkaline and followed by microwave treatment to reduce the valence of the trivalent gold. The synthesized Au NCs gave red fluorescence $(655 \mathrm{~nm})$ under the excitation of $368 \mathrm{~nm}$ [53].

\section{Insulin synthetic protein Au NCs}

Insulin and chloroauric acid was dissolved in sodium phosphate, and reacted for $12 \mathrm{~h}$ at $4{ }^{\circ} \mathrm{C}$. The Insulin- $\mathrm{Au} \mathrm{NCs}$ were obtained after centrifuged at $4000 \mathrm{~g}$ for 30 minutes. The size of Au NCs synthesized by this method was about $0.92 \mathrm{~nm}$ with red fluorescence $(670 \mathrm{~nm})$ under $400 \mathrm{~nm}$ excitation [37].

\section{Lysozyme synthetic protein Au NCs}

Lysozyme was also used as a protective agent and reductant to synthesize the protein cluster. Briefly, lysozyme was mixed with chloroauric acid at a certain molar ratio (7:40). Lysozyme served as a protector and reductant to reduce the trivalent gold to zero in a strong alkaline and $37^{\circ} \mathrm{C}$. The size of the resultant Au clusters is about $1 \mathrm{~nm}$, which emitted red fluorescence $(657 \mathrm{~nm})$ under $360 \mathrm{~nm}$ excitation [33, 36].

\section{Lysozyme Type VI synthetic protein Au NCs}

The researchers also used lysozyme type VI as the protectant and reductant to synthesize protein-gold clusters. They mixed lysozyme type VI and chloroauric acid according to certain molar ratio $(7: 50)$, reacted under strong acid $(\mathrm{pH}=3)$ and $37^{\circ} \mathrm{C}$ for 2 days. The Au NCs synthesized by this method emitted $455 \mathrm{~nm}$ blue fluorescence under the excitation of $380 \mathrm{~nm}$ [67].

If the reaction was performed at $37^{\circ} \mathrm{C}$ overnight with $\mathrm{pH} 12$, and a red fluorescent cluster $(635 \mathrm{~nm})$ with $380 \mathrm{~nm}$ excitation can be obtained [67].

\section{Trypsin-Au NCs}

Trypsin could also be used as a protective agent and reductant to synthesize the protein $\mathrm{Au}$ NCs. Trypsin and chloric acid were mixed in a certain molar ratio (21:125) for $24 \mathrm{~h}$ reaction in a strong alkaline and $37^{\circ} \mathrm{C}$. Trypsin was applied as a protector and reductant to reduce the trivalent gold to a zero-valence gold, where and gold atoms were wrapped by trypsin. The size of synthesized Au NCs was about $2 \mathrm{~nm}$, with red fluorescence $(640 \mathrm{~nm})$ under $360 \mathrm{~nm}$ excitation [68].

\section{Pepsin synthetic protein Au NCs}

The researchers also used pepsin as a protective agent and reductant to synthesize the protein $\mathrm{Au}$ NCs. They mixed pepsin with chloric acid in a certain molar ratio (57:250), after a 12 -h reaction in a strong alkaline and $37^{\circ} \mathrm{C}$, using pepsin as a protector and reductant to reduce the trivalent gold to a zerovalence gold. The synthesized Au NCs were wrapped by pepsin. The size of $\mathrm{Au}$ NCs synthesized by this method is about $1-2 \mathrm{~nm}$, with red fluorescence (670 $\mathrm{nm})$ under $360 \mathrm{~nm}$ excitation [34].

Notably, when pepsin was mixed with chloric acid in a certain molar ratio (57:250), under strong acid $(\mathrm{pH}=1)$ and $37^{\circ} \mathrm{C}$ for $100-\mathrm{h}$, the valence of the trivalent gold was reduced to zero-valence. The synthesized Au NCs were wrapped by pepsin, which emitted green fluorescence $(510 \mathrm{~nm})$ under excitation (330 nm). Moreover, under alkaline environment $(\mathrm{pH}=9)$ and reaction for $24 \mathrm{~h}$, blue fluorescent $\mathrm{Au} \mathrm{NCs}$ (386 and $456 \mathrm{~nm}$ ) can be synthesized under the excitation of $330 \mathrm{~nm}$.

Additionally, other research groups have reported the use of other proteins, such as papain, peroxidase and bacterial recombinant protein enoyl-ACP reductase to synthetize Protein-Au NCs [69-75]. It is likely that the protein and Au NCs form higher oligomeric complexes through a cross-linking mechanism.

\section{Using other protein synthetic protein Au NCs and Self-Assembling}

\section{Self-Assembling Collagen-Gold Hybrid Hydrogel}

In acetic acid solution, collagen and chloroauric acid in a certain molar ratio (141:20000) were adequately mixed at room temperature, and the mixture was reassembled overnight to obtain deep red protein gold hydrogels. The size of gold in the hydrogel was between 20 and $70 \mathrm{~nm}$ [76]. SEM clearly showed that the whole material was a fibrous scaffold structure. 


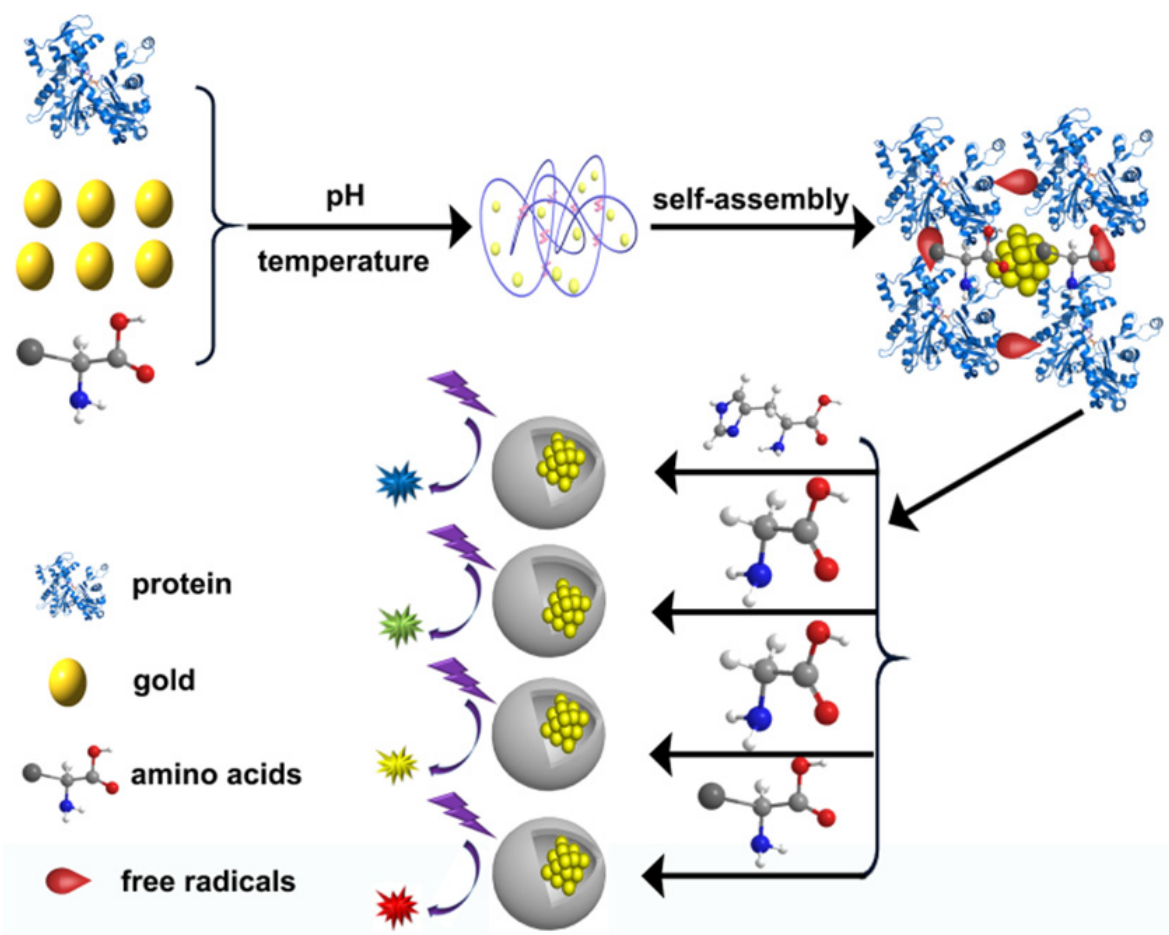

Figure 3. Synthesis of different Protein-Au NCs by amino terminal doping. The reaction process can be considered as self-assembly initiated by free radicals.

Pea protein is loaded (PPI) with gold nanoclusters to self-assemble into composite nanoparticles

First, the PPI was dissolved in a solution containing $6 \mathrm{~mol} / \mathrm{L}$ quinidine hydrochloride and stirred for 3 hours at room temperature to ensure adequate dissolution. Then, the final concentration of $25 \mathrm{mmol} / \mathrm{L}$ dithiothreol was added to the solution. The solution was then dialyzed for two days in a sodium hydroxide solution of $\mathrm{pH}=10$, followed by dialysis in deionized water for one day. The undissolved solids were removed by centrifugation (9000 rpm, $10 \mathrm{~min}$ ). The pretreated PPI powder was obtained after lyophilization. The pretreated PPI was dissolved in deionized water and mixed with chloroauric acid solution in molar ratio (1:50). Under alkaline condition $(\mathrm{pH}=13)$, the gold nanoclusters with a size of about $1 \mathrm{~nm}$ were obtained after reaction for 30 minutes at $60{ }^{\circ} \mathrm{C}$. The gold nanoclusters were excited at $635 \mathrm{~nm}$ by $480 \mathrm{~nm}$ and then the gold clusters were removed from the solution. After full dialysis in ionic water, the $\mathrm{pH}$ value gradually returned to neutrality after 3 days of dialysis. In this process, a protein-gold assembly with a size of about $100 \mathrm{~nm}$ was formed by self-assembly [77].

\section{Modular proteins synthetic protein Au NCs}

Cortajarena et al. designed consensus tetratricopeptide repeat (CTPR) protein and successfully synthesized stable fluorescent gold nanoclusters using self-designed protein, which laid the foundation for controllable synthesis of different metal nanoclusters [21, 78].

\section{Protein-gold self-assembled nanomaterials doped with small molecules}

Inspired by the above protein synthesis methods, scientists find that the key to protein synthesis is the proportion of amino acids. Therefore, in the process of using BSA synthetic Protein-Au NCs, various kinds of amino acids were doped (Figure 3). Finally, several different kinds of protein doped $\mathrm{Au}$ NCs were obtained. Free radicals could be detected from the samples collected during the intermediate process, the reaction mechanism of protein-gold cluster initiated by free radicals was finally determined. Through the results of SDS-PAGE gel, protein crosslinks occurred in the process of gold cluster synthesis, and free radicals were detected in the process of synthesis. We proposed the mechanism of free radicals initiating gold cluster synthesis.

Glycine doped synthetic protein-gold self-assembled nanomaterials

In our previous studies, BSA, glycine and chloroauric acid in a certain molar ratio (3:4000:160) were mixed. We adjusted the $\mathrm{pH}$ value of the mixed solution. In order to find the most suitable $\mathrm{pH}$ conditions for the reaction, we put the reaction under different reaction $\mathrm{pH}$ values. We took advantage of $\mathrm{pH}$ conditions ranging from 1.5 to 12.5 and thus determined the optimal $\mathrm{pH}$ value. Finally, the size of 
BSA, glycine and chlorofluoric acid was about $1.7 \mathrm{~nm}$. The Au NCs of $515 \mathrm{~nm}$ green fluorescence was produced under the excitation of $370 \mathrm{~nm}$. The overall size of the material was about $120 \mathrm{~nm}$. When the BSA and glycine and chlorofluoric acid was synthesized under the condition of $\mathrm{pH}=1.5$, Au NCs of $560 \mathrm{~nm}$ yellow fluorescence were produced with the size of about $1.3 \mathrm{~nm}$, excited by $383 \mathrm{~nm}$. The overall size of the material was about $60 \mathrm{~nm}$. If the reaction was performed with a $\mathrm{pH}$ value of 12.5 , the size of the material was around $1.8 \mathrm{~nm}$, and the Au NC materials with $607 \mathrm{~nm}$ red fluorescence were produced under $372 \mathrm{~nm}$ excitation. The overall size of the material was about $100 \mathrm{~nm}$. Besides, referring to the method of synthesizing Au NCs by pepsin, yellow fluorescent materials would be generated when the $\mathrm{pH}$ of green fluorescent $\mathrm{Au} \mathrm{NC}$ material was transferred to 6.8 for $24 \mathrm{~h} \mathrm{[39].}$

\section{Tryptophan and histidine doped synthetic Protein-} gold self-assembled nanomaterials

We mixed the protein BSA, amino acid tryptophan and chlorotic acid in a certain molar ratio (3:4000:160) to adjust the $\mathrm{pH}$ value of the mixed solution. We found that the optimal $\mathrm{pH}$ value of the reaction was 3 . The reaction solution was mixed in a constant temperature at $\left(37^{\circ} \mathrm{C}\right)$ for $12 \mathrm{~h}$. The size of the composite was about $1.8 \mathrm{~nm}$, and the Au NCs of $480 \mathrm{~nm}$ blue fluorescence was produced under the excitation of $385 \mathrm{~nm}$. The overall size of the material was about $100 \mathrm{~nm}$ [38].

In the same way, we mixed BSA, the group of acid tryptophan and chloroauric acid to a certain molar ratio (3:4000:160) and adjusted the $\mathrm{pH}$ value of the mixed solution. The resultant Au NCs $(\sim 0.9 \mathrm{~nm})$ of $468 \mathrm{~nm}$ blue fluorescence under the excitation of 384 $\mathrm{nm}$ were produced under the condition of 5.5. The overall size of the material was about $140 \mathrm{~nm}$ [39].

\section{Study on the application of protein $\mathrm{Au}$ NCs}

As a kind of fluorescent material, Au NCs are mainly used in the detection of some metal ions based on the enhancement and quenching mechanism of their fluorescence. They can be applied for the detection of mercuric ion [79], the detection of the sulfide ions [80], the small organic molecules and the small molecules of the biological molecules, the detection of the biological samples and the trypsin [81], and the application of the fluorescence properties to the effect of the bioimaging $[79,82,83]$. In addition to the use of Au NCs for catalysis, and the application of protein gold derivatives with the development of protein $\mathrm{Au}$ NCs hybrid materials (Figure 4), here, we summarize the main applications of protein gold nanoclusters, including the environmental and medical detection of metal ions and other important small molecules and proteins, and $t$ nano diagnosis and treatment including nano imaging, CT imaging and targeted drug delivery.

\section{Metal ion detection}

The detection of heavy metals by Au NCs has also been widely studied and applied. The detection of $\mathrm{Hg}$ is the most common, and $\mathrm{Hg}$ exists in the environment of soil and water. $\mathrm{Hg}$ and its derivatives are mainly accumulated in the nervous system, the digestive system, liver and kidney. Remarkably, $\mathrm{Hg}$ can cause damage to respiratory tract mucosa, skin and blood [84]. Therefore, many research groups have been dedicated to the detection of $\mathrm{Hg}$ ions. Xie et al. used the Protein-Au NCs synthesized by BSA to detect the $\mathrm{Hg}$ ion [32]. The mechanism involved that the $\mathrm{Hg}$ ions specifically caused the fluorescence quenching of the Au NCs. Kawasaki et al. used the Au NCs synthesized by trypsin to detect the $\mathrm{Hg}$ ion [68]. The Au NCs could detect $20 \mathrm{nM} \mathrm{Hg}$ ion. Shang and others used the Au NCs synthesized by DHLA to Hg ion at a very low concentration $(0.5 \mathrm{nM})$ [25]. This detection limit was far below the content of $\mathrm{Hg}$ ions in drinking water $(10 \mathrm{nM})$. Ding et al. also prepared the Protein-Au NCs for the detection of $\mathrm{Hg}$ ion [35]. The Protein-Au NCs could be used more conveniently for the detection of $\mathrm{Hg}$ ions. The BSA-Au NCs synthesized by Lin et al. could identify the copper ions [85]. Copper ions could cause the fluorescence quenching of $\mathrm{Au} \mathrm{NCs}$, and they provided the naked eye detection method and the spectrograph detection method. The detection limit reached $10 \mathrm{mM}$ under the naked eye, and the detection limit under the spectrometer could be as low as $0.5 \mathrm{M}$. In addition, Ding and others used DTT as a protector and reducing agent to quickly synthesize $\mathrm{Au}$ NCs, which also identified the copper ions. [86] Copper ions caused the fluorescence quenching of Au NCs, while other metal ions failed to cause the quenching of $\mathrm{Au}$ NCs. The detection limit of copper ion was low $(80$ $\mathrm{nM})$ and the performance was stable. These synthesized $\mathrm{Au}$ NCs could be used to effectively detect the copper ions in the serum.

Kawasaki et al. used Au NCs synthesized by pepsin to detect lead ions, and lead ions could enhance the fluorescence of Au NCs [34]. Considering that silver ions enhanced the fluorescence of $\mathrm{Au} \mathrm{NCs,}$ BSA-Au NCs synthesized by microwave method also showed potential in detecting silver ions [52].

\section{Anion detection}

In addition to the detection of metal cations, anions could also be detected by Au NCs. Chen and 
others used the DNA synthesized to detect sulfur ions, which could be further used for environmental detection [80]. The Au NCs may provide protection from sulfide-caused harm to human beings. In addition, Liu and others also tested cyanide by $\mathrm{Au}$ NCs, which was a highly toxic pollutant and a great threat to human health [87].

\section{Small molecule detection}

Park et al. used BSA synthetic Au NCs to detect sulfhydryl small molecules glutathione (GSH), cysteine (Cys) and homocysteine (Hcy) [88]. The detection mechanism was that the fluorescence quenching of $\mathrm{Au}$ NCs could be caused by the aid of $\mathrm{Hg}$ ions, and the sulfhydryl group would chelate with the $\mathrm{Hg}$ ions to destroy the quenching. The indirect detection of the relationship between three clusters of $\mathrm{Au} \mathrm{NCs,} \mathrm{Hg} \mathrm{ions} \mathrm{and} \mathrm{sulfhydryl} \mathrm{molecules} \mathrm{were}$ skillfully applied. Dong et al. also used the indirect detection method to detect glucose by using BSA Au NCs [89]. The glucose oxidase was used to decompose glucose to produce hydrogen peroxide that quenches the fluorescence of Au NCs. Thus, the effect of glucose was detected. Chen and others used the BSA Au NCs to detect ciprofloxacin [90]. They first quenched the
$\mathrm{Au}$ NCs by copper ions, and then used the carboxyl group on the ciprofloxacin to destroy the Au NCs fluorescence by chelating the copper ions. The BSA $\mathrm{Au}$ NCs played a role in the detection of ciprofloxacin [90]. Dai et al. also used BSA-Au NCs to detect melamine [91]. Melamine was used as an additive in infant milk powder to improve the nitrogen content in milk powder; Dai and others recovered the fluorescence quenching of Au NCs according to the chelating effect of melamine on $\mathrm{Hg}$ ions, $\mathrm{Au} \mathrm{NCs}$ played a role in detection of melamine. Moreover, the detection limits of this method was lower than $0.15 \mathrm{M}$, far below the national food safety requirement.

\section{Protein detection}

Chen et al. designed $\mathrm{Au}$ NCs for protein detection based on the binding principle of glutathione (GSH) and GST in protein purification [92]. First, they synthesized the Au NCs protected by GSH, and then used the special interaction between glutathione and GST to detect the GST protein in the solution. Proteins were detected by observing the changes of gold cluster fluorescence with the naked eye or a fluorescence spectrometer.

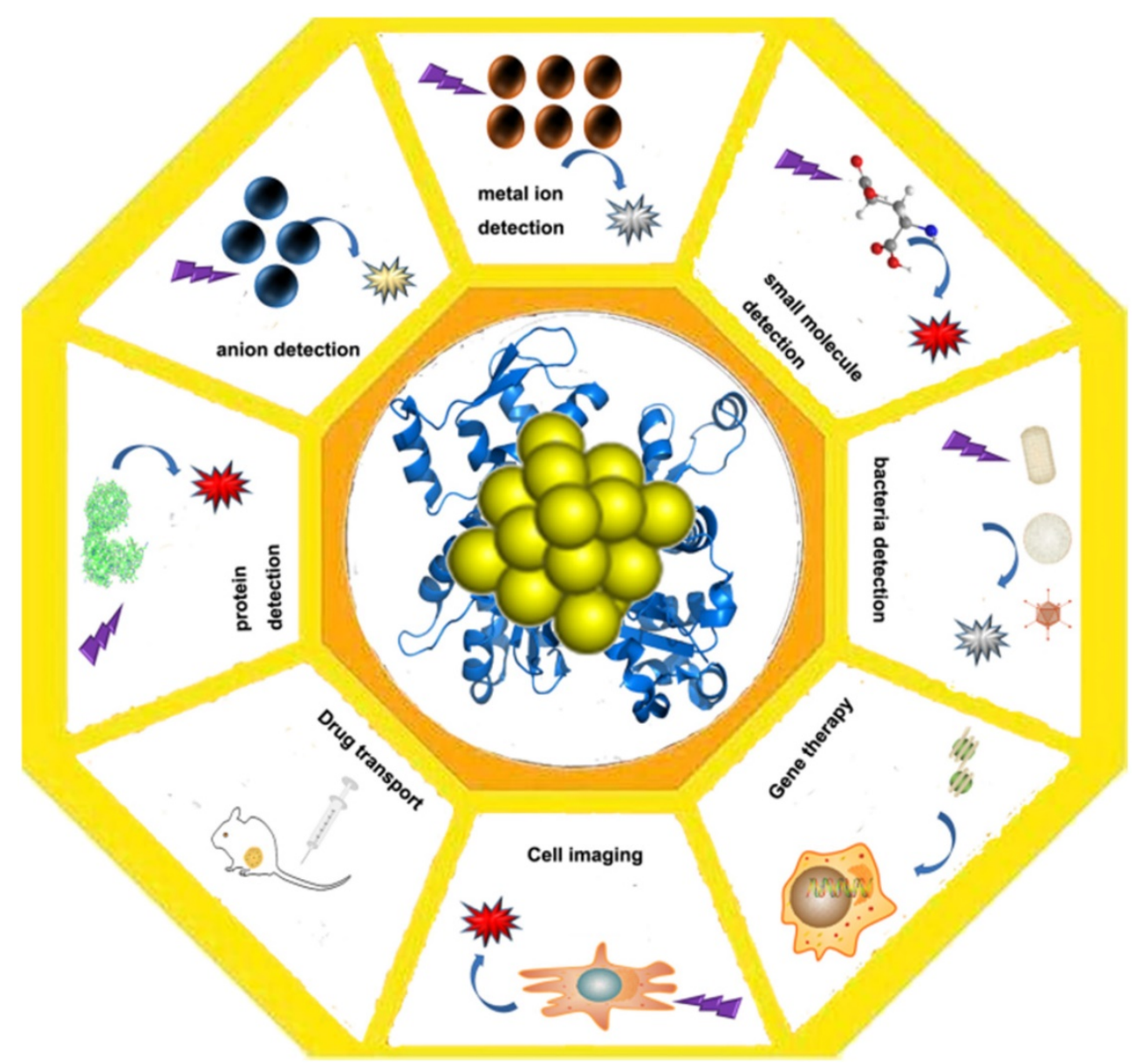

Figure 4. Application of protein-gold nanomaterials. Protein-gold nanomaterials could be used for the detection of ions and small molecules, cell imaging, drug delivery and gene therapy. 


\section{Bacteria detection}

Chan et al. developed HSA stabilized Au NCs, which was used as a selective luminescence probe for Staphylococcus aureus and methicillin resistant Staphylococcus aureus [93]. Also, Ji et al. designed and prepared four kinds of Protein-Au NCs probes for simple, rapid, and accurate identification of bacteria [94].

\section{Cell imaging application}

Wang et al. used BSA-protected $\mathrm{Au}$ NCs for identifying specific breast cancer cell SK-BR3, the primary method is to modify Hessaitin (Herceptin) a specific monoclonal antibody against the surface protein of metastatic breast cancer cells on the surface of the BSA Au NCs [95]. Shang et al. used the synthetic DHLA-Au NCs for cell imaging [25]. The $\mathrm{Au}$ NCs were more stable in the cells, be used to test the temperature changes in the cells with Au NCs. Ding et al. also synthesized gold doped cluster materials and used them for cell imaging of fungi and animal cells $[38,39,54,76,77]$.

\section{CT imaging application}

Protein-gold nanoclusters not only make use of their luminescent properties for cell imaging, but also have great Stokes potential (Stokes). In recent years, they have also been developed for CT imaging because of its advantages such as displacement and high X-ray absorption efficiency. For instance, Zhang et al synthesized gold nanoclusters using reduced glutathione as template for CT imaging, which has great potential compared with traditional clinical CT imaging $[96,97,98]$.

\section{Transport of drugs}

Hong et al. designed a drug delivery system for gold nanomaterials. When the drug delivery system enters the cell, the drug is released under the action of reduced glutathione in the cell, thus completing the drug delivery [99]. Ding et al. used tryptophan doped hybrids to load the drug Adriamycin (Dox) into cells through electrostatic adsorption [38]. In the cell, drug release is caused by the weak acidic environment of cancer cells, and drug delivery is completed.

\section{Gene transport}

Li et al. used the hybrids doped by tryptophan to load the plasmids expressing green fluorescent protein into the cells and expressed the green fluorescent protein in the yeast cells [100]. Zhang et al. used the DTT protected gold nanoclusters to load the plasmids expressing green fluorescent protein into the cells and expressed the green fluorescent protein in the yeast cells [101]. It also opened up a new way for gene therapy by using protein Au NCs instead of viruses.

\section{Conclusions and outlook}

Protein gold nanoclusters are novel nanomaterials with unique physical and chemical properties, which show great potential in many biomedical applications. In the past decade, the research on protein-gold hybrid materials, from the synthetic method to the capping agent selection, has made significant progress. In addition, the study on the characterization of materials has gradually expanded. These researches also focus on the synthesis and in-depth exploration of the synthetic mechanism.

The advantages of fluorescent protein-gold hybrid nanomaterials include simple preparation, environmentally friendly synthesis methods, stable photochemical properties, and low toxicity. In addition, some excellent functions of Au NCs are also elucidated. On the one hand, Au NCs can be used to detect substances from heavy metal ions, small organic molecules and large molecules. The detection method is simple, and the detection performance is stable and the selectivity is high. It is particularly important to develop new probes for detecting global climate change and environmental pollution, especially marine and atmospheric pollution. On the other hand, to cope with the global epidemic such as COVID-19, it's an important direction using protein gold cluster probes for rapid nucleic acid detection, disease diagnosis and reducing diagnostic costs. Besides, the luminescence of protein-nanoclusters is stable, and resistant to the interference such as salt and $\mathrm{pH}$. These Au NCs are also highly biocompatiable and possess decent ant-photo bleaching properties. The complex interactions between nanomaterials and biological systems have attracted great attention of researchers. As a new type of nanomaterials for diagnosis and treatment, protein-gold nanoclusters have shown a lot of potential biomedical applications. Understanding their behavior in the biological environment is an important prerequisite for practical medical applications in the future. Although this field is still in the early stage of research, some researches have clearly shown the significant effects of protein adsorption on the physicochemical properties of gold nanoclusters, and the key roles of protein adsorption, charge interaction and surface ligands on the biological effects of metal nanoclusters [102, 103, 104]. $\mathrm{Au}$ NCs are important materials for cell imaging in the future. Not only that, $\mathrm{Au}$ NCs are also good carriers to carry the necessary ingredients (e.g., small molecule drugs, DNAs and proteins) into target cells (Figure 5). Based on the good drug carrier and 
modifiable characteristics, further development of protein gold clusters as targeted drugs for tumor and cardiovascular and nucleic acid vaccine has broad application prospects. In order to further understand the behavior of protein capped metal nanoclusters in the biological environment, further research is needed. First, the structure and physicochemical properties of protein-gold nanoclusters are need to be characterized in more detail, so that the effects of specific key parameters can be determined quantitatively. More in-depth and systematic research on protein-gold nanoclusters in vivo and their effects on immune system is also the direction of future efforts.

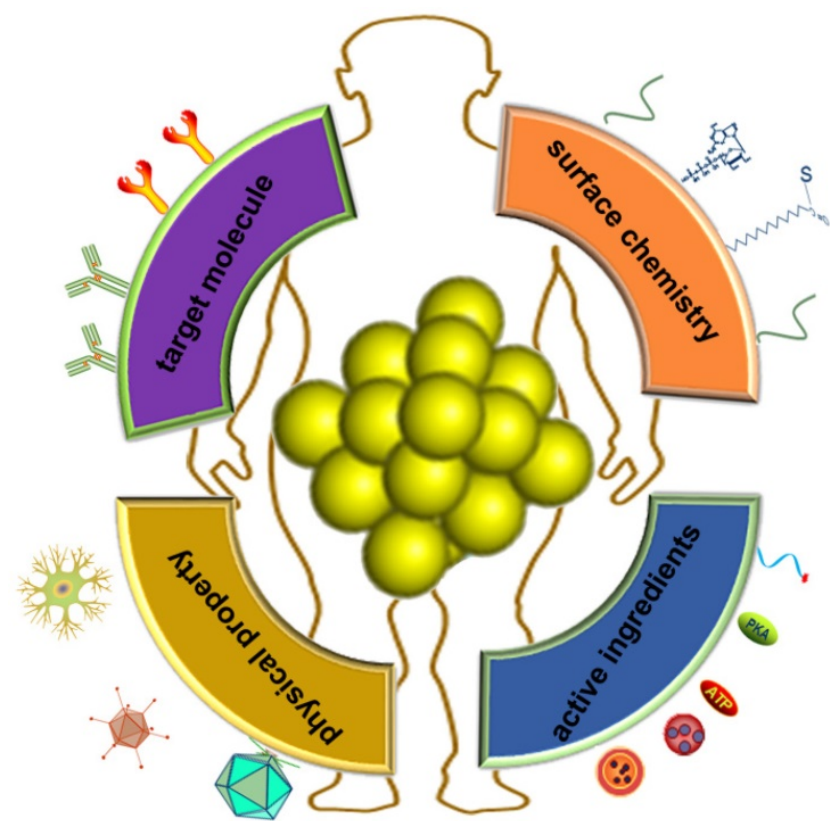

Figure 5. Application prospect of Protein-gold nanomaterials in integration of modification and diagnosis and treatment.

\section{Acknowledgements}

This work was supported by the A Project of Shandong Province Higher Educational Science and Technology Program (No. J18KA127), Qingdao University Research Fund, the National Natural Science Foundation of China (NSF) (No. 21372097).

\section{Author Contributions}

The manuscript was written through the contributions of all authors. All authors have approved the final version of the manuscript.

\section{Competing Interests}

The authors have declared that no competing interest exists.

\section{References}

1. Jadzinsky PD, Calero G, Ackerson CJ, Bushnell DA, Kornberg RD. Structure of a thiol monolayer-protected gold nanoparticle at 1.1 angstrom resolution. Science. 2007; 318: 430-433.

2. Daniel MC, Astruc D Gold nanoparticles: Assembly, supramolecular chemistry, quantum-size-related properties, and applications toward biology, catalysis, and nanotechnology. Chem. Rev. 2004; 104 (1): 293-346.

3. Rosi NL, Mirkin CA. Nanostructures in Biodiagnostics. Chem. Rev. 2005; 105 (4): 1547-1562.

4. Kawabata A. Electronic Properties of Metallic Fine Particles. Surf. Rev. Lett. 1996; 3: 9-12.

5. Mooradian A. Photoluminescence of Metals. Phys. Rev. Lett. 1969; 22:185-189.

6. Takagahara T. Effects of dielectric confinement and electron-hole exchange interaction on excitonic states in semiconductor quantum dots. Phys. Rev. B. 1993; 47: $4569-4584$.

7. Anderson BP, Kasevich MA. Macroscopic Quantum Inter-ference from Atomic Tunnel Arrays. Science. 1998; 282: 1686-1689.

8. Zheng J, Nicovich PR, Dickson RM. Highly Fluorescent Noble Metal Quantum Dots. Annu. Rev. Phys. Chem. 2007; 58: 409-431.

9. Liu YL, Ai KL, Cheng XL, Huo LH, Lu LH. Gold-Nanocluster-Based Fluorescent Sensors for Highly Sensitive and Selective Detection of Cyanide in Water. Adv. Funct. Mater. 2010; 20: 951-956.

10. Zhu MZ, Aikens CM, Hollander FJ, Schatz GC, Jin RC. Correlating the crystal structure of A thiol-protected Au-25 cluster and optical properties. J. Am. Chem. Soc. 2008; 130: 5883-5885.

11. Zeng CJ, Chen YX, Gao L, Jin RC. Synthesis of an Au44 (SR) 28 nanocluster: structure prediction and evolution from Au28 (SR) 20, Au36 (SR) 24 to Au44 (SR). Chem. Commun. 2014; 50: 55-57.

12. Baksi A, Pradeep T, Yoon B, Yannouleas C, Landman U. Bare clusters derived from protein templates: Au25+, Au38+ and Au102+. ChemPhysChem. 2013; 14: $1272-1282$

13. Qian HF, Zhu MZ, Wu ZK, Jin RC. Quantum sized gold nanoclusters with atomic precision. Accounts. Chem. Res. 2012; 45:1470-1479.

14. $\mathrm{Wu} \mathrm{ZK}$, Jin RC. On the ligand's role in the fluorescence of gold nanoclusters. Nano. Lett. 2010, 10: 2568-2573.

15. Aikens CM. Electronic structure of ligand-passivated gold and silver nanoclusters. J. Phys. Chem. Lett. 2010; 2: 99-104.

16. Zhu M, Aikens CM, Hendrich MP. Reversible switching of magnetism in thiolate-protected Au25 superatoms. J. Am. Chem. Soc. 2009; 131: 2490-2492.

17. Zeng CJ, Li T, Das A, Ros NL, Jin RC. Chiral structure of thiolate-protected 28-gold-atom nanocluster determined by X-ray crystallography. J. Am. Chem. Soc. 2013; 135: 10011-10013.

18. Zhu MZ, Qian HF, Meng XM, Jin SS, Wu ZK, Jin RC. Chiral Au25 nanospheres and nanorods: Synthesis and insight into the origin of chirality. Nano. Lett. 2011; 11(9): 3963-3969.

19. Yuan X, Luo ZT, Yu Y, Yao OF, Xie JP. Luminescent noble metal nanoclusters as an emerging optical probe for sensor development. Chem- Asian. J. 2013; 8: 858-871.

20. Shang L, Dong SJ, Nienhaus GU. Ultra-small fluorescent metal nanoclusters: synthesis and biological applications. Nano Today. 2011; 6: 401-418.

21. Aires A, Llarena I, Moller M, Castro-Smirnov J, Caba-nillas-Gonzalez J, Cortajarena AL. A Simple Approach to Design Proteins for the Sustainable Synthesis of Metal Nanoclusters. Angew. Chem. Int. Ed. 2019; 58: 6214-6219.

22. Liu YL, Zhu J, Weng GJ, Li JJ, Zhao JW. Gold nanotubes: synthesis, properties and biomedical applications. Microchim. Acta. 2020; 187(11): 612.

23. Nasaruddin RR, Chen TK, Yao QF, Zang SQ, Xie JP. Toward greener synthesis of gold nanomaterials: From biological to biomimetic synthesis. Coordin. Chem. Rev. 2020; 426: 213540.

24. Lin CAJ, Lee $\mathrm{CH}$, Hsieh JT, Wang HH, Li JK, Shen JL, Chan WH, Yeh HI, Chang WH. Synthesis of Fluorescent Metallic Nanoclusters Toward Biomedical Application: Recent Progress and Present Challenges. J. Med. Biol. Eng. 2009; 29: 276-283.

25. Shang L, Yang LX, Stockmar F, Popescu R, Trouillet V, Bruns M, Gerthsen D, Nienhaus GU. Microwave-assisted rapid synthesis of luminescent gold nanoclusters for sensing $\mathrm{Hg} 2+$ in living cells using fluorescence imaging. Nanoscale. 2012; 4: 4155-4160.

26. Zheng I, Jeffrey TP, Robert MB. High quantum yield blue emission from water-soluble Au8 nanodots. J. Am. Chem. Soc. 2003; 125: 7780-7781.

27. Gonzalea BS, Rodriguez MJ, Blanco C, Rivas J, Lopez-Quintela MA, Martinho JMG. One step synthesis of the smallest photoluminescent and paramagnetic PVP-protected gold atomic clusters. Nano. Lett. 2010; 10: 4217-4221.

28. Zhou RJ, Shi MM, Chen XQ, Wang M, Chen HZ. Atom-ically monodispersed and fluorescent sub-nanometer gold clusters created by biomolecule-assisted etching of nanometer-sized gold particles and rods. Chem- Eur. J. 2009; 15: 4944-4951.

29. Xie JP, Zheng YG, Yin JY. Protein-directed synthesis of highly fluorescent gold nanoclusters. J. Am. Chem. Soc. 2009; 131: 888-889.

30. Liu GY, Shao Y, Wu F, Xu SJ, Peng J, Liu LL. DNA-hosted fluorescent gold nanoclusters: sequence-dependent formation. Nanotechnology. 2013; 24 : 015503.

31. Sheng JP, Jiang XX, Wang LQ, Yang MH, Liu YN. Biomimetic Mineralization Guided One-Pot Preparation of Gold Clusters Anchored Two-Dimensional $\mathrm{MnO} 2$ Nanosheets for Fluorometric/Magnetic Bimodal Sensing. Anal. Chem. 2018; 90 (4): 2926-2932. 
32. Xie JP, Zheng YG, Ying JY. Highly selective and ultrasensitive detection of $\mathrm{Hg} 2+$ based on fluorescence quenching of $\mathrm{Au}$ nanoclusters by $\mathrm{Hg} 2+-\mathrm{Au}+$ interactions. Chem. Commun. 2010; 46: 961-963.

33. Wei H, Wang ZD, Yang LM, Tian SL, Hou CJ, Lu Y. Lysozyme-stabilized gold fluorescent cluster: Synthesis and application as $\mathrm{Hg} 2+$ sensor. Analyst. 2010; 135: 1406-1410.

34. Kawasaki H, Hamaguchi K, Osaka I, Arakawa R. ph-Dependent Synthesis of Pepsin-Mediated Gold Nanoclusters with Blue Green and Red Fluorescent Emission. Adv. Funct. Mater. 2011; 21: 3508-3515

35. Ding H, Li HW, Liu PC, Hiltunen JK, Wu YQ, Chen ZJ, Shen JC. Templated in-situ synthesis of gold nanoclusters conju-gated to drug target bacterial enoyl-ACP reductase, and their appli-cation to the detection of mercury ions using a test stripe. Micro-chim Acta. 2014; 181: 1029-1034.

36. Wei H, Wang ZD, Zhang J, House S, Gao YG, Yang LM, Robinson H, Tan LH, Xing H, Hou CJ, Robertson IM, Zuo JM, Lu Y. Time-dependent, proteindirected growth of gold nanoparticles within a single crystal of lysozyme. Nat. Nanotechnol. 2011; 6: 93-97.

37. Liu CL, Wu HT, Hsiao YH, Lai CW, Shih CW, Peng YK, Tang KC, Chang HW, Chien YC, Hsiao JK, Cheng JT, Chou PT. Insulin-Directed Synthesis of Fluorescent Gold Nanoclusters: Preservation of Insulin Bioactivity and Versatility in Cell Imaging. Anew. Chem. Int. Ed. 2011; 50: 7056-7060.

38. Ding H, Yang DY, Zhao C, Song ZK, Liu PC, Wang Y, Chen ZJ, Shen JC. Protein-Gold Hybrid Nanocubes for Cell Imag-ing and Drug Delivery. ACS. Appl. Mater. Inter. 2015; 7 (8): 4713-4719.

39. Ding H, Li HW, Wang XL, Zhou YF, Li ZH, Hiltunen JK, Shen JC, Chen ZJ. Expanding Toolbox of Imageable Protein-Gold Hybrid Materials. Chem. Mater. 2017; 29(19): 8440-8448.

40. Mathew MS, Joseph K. Green Synthesis of Gluten-Stabilized Fluorescent Gold Quantum Clusters: Application as Turn-On Sensing of Human Blood Creatinine. ACS Sustain. Chem. Eng. 2017; 5: 4837-4845.

41. Xiao B, Zhou XX, Xu HX, Wu BH, Hu D, Hu HJ, Pu KY, Zhou ZX, Liu XR, Tang JB, Shen YQ. Integration of Polymerization and Biomineralization as a Strategy to Facilely Synthesize Nanotheranostic Agents. ACS Nano. 2018; 12: 12682-12691.

42. Wang XS, Yang DP, Huang P, Li M, Li C, Chen D, Cui DX. Hierarchically assembled $\mathrm{Au}$ microspheres and sea urchin-like architectures: formation mechanism and SERS study. Nanoscale. 2012; 4: 7766-7772.

43. Zhang XD, Chen J, Luo ZT, Wu D, Shen X, Song SS, Sun YM, Liu PX, Zhao J, Huo SD, Fan SJ, Fan FY, Liang XJ, Xie JP. Enhanced Tumor Accumulation of Sub-2 nm Gold Nanoclusters for Cancer Radiation Therapy. Adv. Healthc. Mater. 2014; 3: 133-141.

44. Yu Y, Luo ZT, Teo CS, Tan YN, Xie JP. Tailoring the protein conformation to synthesize different-sized gold nanoclusters. Chem. Commun. 2013; 49: 9740-9742.

45. Guan GJ, Zhang SY, Cai YQ, Liu SH, Bharathi MS, Low M, Yu Y, Xie JP, Zheng YG, Zhang YW, Han MY. Convenient purification of gold clusters by co-precipitation for improved sensing of hydrogen peroxide, mercury ions and pesticides. Chem. Commun. 2014; 50: 5703-5705.

46. Zhang XD, Luo ZT, Chen J, Song SS, Yuan X, Shen X, Wang H, Sun YM, Gao K, Zhang LF, Fan SJ, Leong DT, Guo ML, Xie JP. Ultrasmall GlutathioneProtected Gold Nanoclusters as Next Generation Radiotherapy Sensitizers with High Tumor Uptake and High Renal Clearance. Sci. Rep. 2015; 5: 8669.

47. Xing RR, Jiao TF, Yan LY, Ma GH, Liu L, Dai LR, Li JB, Möhwald H, Yan XH. Colloidal Gold-Collagen Protein Core-Shell Nanoconjugate: One-Step Biomimetic Synthesis, Layer-by-Layer Assembled Film, and Controlled Cell Growth. ACS Appl. Mater. Interfaces. 2015; 7: 24733-24740.

48. Xie JP, Lee JY, Wang DIC. Synthesis of Single-Crystalline Gold Nanoplates in Aqueous Solutions through Biomineralization by Serum Albumin Protein. J. Phys. Chem. C. 2007; 111: 10226-10232.

49. Singh AV, Batuwangala M, Mundra R, Mehta K, Patke S, Falletta E, Patil R, Gade WN. Biomineralized Anisotropic Gold Microplate-Macrophage Interactions Reveal Frustrated Phagocytosis-like Phenomenon: A Novel Paclitaxel Drug Delivery Vehicle. ACS Appl. Mater. Interfaces. 2014; 6: 14679-14689.

50. Chiku M, Ivandini TA, Kamiya A, Fujishima A, Einaga Y. Direct electrochemical oxidation of proteins at conductive diamond electrodes. J. Electroanal. Chem. 2008; 612: 201-207.

51. Sasidharan S, Bahadur D, Srivastava R. Rapid, One-Pot, Protein-Mediated Green Synthesis of Gold Nanostars for Computed Tomographic Imaging and Photothermal Therapy of Cancer. ACS Sustain. Chem. Eng. 2017; 5: 10163-10175.

52. Yue $Y$, Liu TY, Li HW, Liu ZY, Wu YQ. Microwave-assisted synthesis of BSA-protected small gold nanoclusters and their fluorescence-enhanced sensing of silver(I) ions. Nanoscale. 2012; 4: 2251-2254.

53. Yan L, Cai YQ, Zheng BZ, Yuan HY, Guo Y, Xiao Dan, Choi MMF. Microwave-assisted synthesis of BSA-stabilized and HSA-protected gold nanoclusters with red emission. J. Mater. Chem. 2012; 22: 1000-1005.

54. Wang LQ, Jiang XX, Zhang Min, Yang M, Liu YN. In situ Assembly of Au Nanoclusters within Protein Hydrogel Networks. Chem. Asian J. 2017; 12: $2374-2378$

55. Liu PC, Wang H, Hiltunen JK, Chen ZJ, Shen JC. Cross-Linked Proteins with Gold Nanoclusters: A Dual-Purpose pH-Responsive Material for Controllable Cell Imaging and Antibiotic Delivery. Part. Part. Syst. Charact. 2015; 32: 749755.
56. Khullar P, Goshisht MK, Moudgil L, Singh G, Mandial D, Kumar H, Ahluwalia GK, Bakshi MS. Mode of Protein Complexes on Gold Nanoparticles Surface: Synthesis and Characterization of Biomaterials for Hemocompatibility and Preferential DNA Complexation. ACS Sustain. Chem. Eng. 2017; 5: 1082-1093.

57. Aryal S, Bahadur R, Bhattarai KCSR, Prabu P, Kim HY. Immobilization of collagen on gold nanoparticles: preparation, characterization, and hydroxyapatite growth. J. Mater. Chem. 2006; 16: 4642-4648.

58. Zhang JJ, Gu MM, Zheng TT, Zhu JJ. Synthesis of Gelatin-Stabilized Gold Nanoparticles and Assembly of Carboxylic Single-Walled Carbon Nanotubes/Au Composites for Cytosensing and Drug Uptake. Anal. Chem. 2009; 81: 6641-6648.

59. Javed I, Sun YX, Adamcik J, Wang B, Kakinen A, Pilkington EH, Ding F, Mezzenga R, Davis TP, Ke PC. Cofibrillization of Pathogenic and Functional Amyloid Proteins with Gold Nanoparticles against Amyloidogenesis. Biomacromolecules. 2017; 18: 4316-4322.

60. Zang JC, Li CG, Zhou K, Dong HS, Chen B, Wang FD, Zhao GH. Nanomolar $\mathrm{Hg} 2+$ Detection using $\beta$-Lactoglobulin-Stabilized Fluorescent Gold Nanoclusters in Beverage and Biological Media. Anal. Chem. 2016; 88: 10275-10283.

61. Leng YM, Jiang K, Zhang WT, Wang YH. Synthesis of Gold Nanoparticles from $\mathrm{Au}(\mathrm{I})$ Ions That Shuttle to Solidify: Application on the Sensor Array Design. Langmuir. 2017; 33: 6398-6403.

62. Mahal A, Khullar P, Kumar H, Kaur G, Singh N, Jelokhani-Niaraki M, Bakshi MS. Green Chemistry of Zein Protein Toward the Synthesis of Bioconjugated Nanoparticles: Understanding Unfolding, Fusogenic Behavior, and Hemolysis. ACS Sustain. Chem. Eng. 2013; 1: 627-639.

63. Nobusawa $\mathrm{K}$, Okamoto $\mathrm{N}$, Chong KSL, Lin X, Iwahori $\mathrm{K}$, Yamashita I. Dispersed Gold Nanoparticle Array Produced by Apoferritins Utilizing Biomineralization and Chemical Conversion. ACS Omega. 2017; 2: 1424-1430.

64. Chaudhari K, Xavier PL, Pradeep T. Understanding the Evolution of Luminescent Gold Quantum Clusters in Protein Templates. ACS Nano. 2011; 5: 8816-8827.

65. Wang Y, Chen JT, Yan XP. Fabrication of Transferrin Functionalized Gold Nanoclusters/Graphene Oxide Nanocomposite for Turn-On Near-Infrared Fluorescent Bioimaging of Cancer Cells and Small Animals. Anal. Chem. 2013; 85: 2529-2535.

66. Zou LH, Oi W, Huang RL, Su RX, Wang MF, He ZM. Green Synthesis of a Gold Nanoparticle-Nanocluster Composite Nanostructures Using Trypsin as Linking and Reducing Agents. ACS Sustain. Chem. Eng. 2013; 1: 1398-1404.

67. Chen TH, Tseng WL. (Lysozyme Type VI) -Stabilized Au8 Clusters: Synthesis Mechanism and Application for Sensing of Glutathione in a Single Drop of Blood. Small. 2012; 8: 1912-1919.

68. Kawasaki H, Yoshimura K, Hamaguchi K, Arakawa R. Trypsin-Stabilized Fluorescent Gold Nanocluster for Sensitive and Selective $\mathrm{Hg} 2+$ Detection. Anal Sci. 2011; 27: 591-594.

69. Biswas A, Banerjee S, Gart EV, Nagaraja AT, McShane MJ. Gold Nanocluster Containing Polymeric Microcapsules for Intracellular Ratiometric Fluorescence Biosensing. ACS Omega. 2017; 2(6): 2499-2506.

70. Muthukumar T, et al. Green synthesis of gold nanoparticles and their enhanced synergistic antitumor activity using HepG2 and MCF7 cells and its antibacterial effects. Process. Biochem. 2016; 51: 384-391.

71. Dauthal P, Mukhopadhyay M. Prunus domestica Fruit Extract-Mediated Synthesis of Gold Nanoparticles and Its Catalytic Activity for 4-Nitrophenol Reduction. Ind. Eng. Chem. Res. 2012; 51(40): 13014-13020.

72. Dauthal P, Mukhopadhyay M. In-vitro free radical scaveng-ing activity of biosynthesized gold and silver nanoparticles using Prunus armeniaca (apricot) fruit extract. J Nanopart Res. 2013; 15: 1366.

73. Wen F, Dong YH, Feng L, Wang S, Zhang SC, Zhang XR. Horseradish Peroxidase Functionalized Fluorescent Gold Nanoclusters for Hydrogen Peroxide Sensing. Anal. Chem. 2011; 83(4): 1193-1196.

74. West AL Griep MH Cole DP Karna SP DNase 1 Retains Endodeoxyribonuclease Activity Following Gold Nanocluster Synthesis. Anal. Chem. 2014; 86(15): 7377-7382.

75. Liu GY, Shao Y, Ma K, Cui OH, Wu F, Xu SJ. Synthesis of DNA-templated fluorescent gold nanoclusters. Gold. Bull. 2012; 45: 69-74.

76. Xing RR, Liu K, Jiao TF, Zhang N, Ma K, Zhang RY, Zou QL, Ma GH, Yan XH. An Injectable Self-Assembling Collagen-Gold Hybrid Hydrogel for Combinatorial Antitumor Photothemal/ Photodynamic Therapy. Adv. Mater. 2016; 28: 3669-3676.

77. Li Z, Peng HB, Liu JL, Tian Y, Yang WL, Yao JR, Shao ZZ, Chen X. Plant Protein-Directed Synthesis of Luminescent Gold Nanocluster Hybrids for Tumor Imaging. ACS. Appl. Mater. Inter. 2018; 10: 83-90.

78. Couleaud P, Adan-Bermudez S, Aires A, Mejias SH, Sot B, Somoza A, Cortajarenea AL. Designed Modular Proteins as Scaffolds to Stabilize Fluorescent Nanoclusters. Biomacromolecule. 2015; 16: 3836-3844.

79. Lee JS, Han MS, Mirkin CA. Colorimetric Detection of Mercuric Ion (Hg2+) in Aqueous Media using DNA-Functionalized Gold Nanoparticles. Angew. Chem. Int. Ed. 2007; 119: 4171-4174.

80. Chen WY, Lan GY, Chang HT. Use of Fluorescent DNA-Templated Gold/ Silver Nanoclusters for the Detection of Sulfide Ions. Anal. Chem. 2011; 83(24): 9450-9455.

81. Hu LZ, Han S, Parveen S, Yuan YL, Zhang L, Xu GB. Highly sensitive fluorescent detection of trypsin based on BSA-stabilized gold nanoclusters. Biosens. Bioelectron. 2012; 32: 297-299. 
82. Wang JL, Zhang G, Li QW, Jiang H, Liu CY, Amatore C, Wang XM. In vivo self-bio-imaging of tumors through in situ biosynthesized fluorescent gold nanoclusters. Sci. Rep-UK. 2013; 3: 1157.

83. Khandelia R, Bhandari S, Pan UN, Ghosh SS, Chatto-padhyay A. Gold Nanocluster Embedded Albumin Nanoparticles for Two-Photon Imaging of Cancer Cells Accompanying Drug Delivery. Small. 2015; 11: 4075-4081.

84. Holmes $\mathrm{P}$, James KAF, Levy LS. Is low-level environmental mercury exposure of concern to human health? Sci. Total. Environ. 2009; 408: 171-182.

85. Lin ZJ, Luo FQ, Dong TQ, Zheng LY, Wang YX, Chi YW, Chen GN. Recyclable fluorescent gold nanocluster mem-brane for visual sensing of copper (II) ion in aqueous solution. Analyst. 2012; 137: 2394-2399.

86. Ding H, Liang CS, Sun KB, Wang H, Hiltunen JK, Chen ZJ, Shen JC. Dithiothreitol-capped fluorescent gold nanoclusters: An efficient probe for detection of copper (II) ions in aqueous solution. Biosens. Bioelectron. 2014; 59: 216-220.

87. Liu YL, Ai KL, Cheng XL, Huo LH, Lu LH. Gold-Nanocluster-Based Fluorescent Sensors for Highly Sensitive and Selective Detection of Cyanide in Water. Adv. Funct. Mater. 2010; 20: 951-956.

88. Park KS, Kim MI, Woo MA, Park HG. A label-free method for detecting biological thiols based on blocking of $\mathrm{Hg} 2+-$ quenching of fluorescent gold nanoclusters. Biosens. Bioelectron. 2013; 45: 65-69.

89. Jin LH, Shang L, Guo SJ, Fang YX, Wen D, Wang L, Yin JY, Dong SJ. Biomolecule-stabilized Au nanoclusters as a fluorescence probe for sensitive detection of glucose. Biosens. Bioelectron. 2011; 26: 1965-1969.

90. Chen ZG, Qian SH, Chen JH, Cai J, Wu SY, Cai ZP. Protein-templated gold nanoclusters-based sensor for off-on detection of ciprofloxacin with a high selectivity. Talanta. 2012; 94: 240-245.

91. Dai HC, Shi Y, Wang YL, Sun YJ, Hu JT, Ni PJ, Li Z. Label-free turn-on fluorescent detection of melamine based on the anti-quenching ability of $\mathrm{Hg} 2+$ to gold nanoclusters. Biosens. Bioelectron. 2014; 53: 76-81.

92. Huang CC, Chiang CK, Lin ZH, Lee $\mathrm{KH}$, Chang HT. Bioconjugated gold nanodots and nanoparticles for protein assays based on photoluminescence quenching. Anal. Chem. 2008; 80: 1497-1504.

93. Chan PH, Chen YC. Human Serum Albumin Stabilized Gold Nanoclusters as Selective Luminescent Probes for Staphylococcus aureus and MethicillinResistant Staphylococcus aureus. Anal. Chem. 2012; 84 (21): 8952-8956.

94. Ji HW, Wu L, Pu F, Ren JS, Qu XG. Point-of-Care Identification of Bacteria using Protein-Encapsulated Gold Nanoclusters. Adv. Healthcare. Mater. 2018; 7: 1701370.

95. Wang YL, Chen JJ, Irudayaraj J. Nuclear Targeting Dynamics of Gold Nanoclusters for Enhanced Therapy of HER2+ Breast Cancer. ACS Nano. 2011; 5(12): 9718-9725.

96. Hong R, Han G, Fernandez JM, Kim BJ, Forbes NS, Rotello VM. GlutathioneMediated Delivery and Release Using Monolayer Protected Nanoparticle Carriers. J. Am. Chem. Soc. 2006; 128(4): 1078-1079.

97. Hainfeld JF, Slatkin DN, Focella TM, Smilowitz HM. Gold nanoparticles: a new $X$-ray contrast agent. Brit. J. Radiol. 2006; 79: 248-253.

98. Zhang $\mathrm{YY}, \mathrm{Wu} \mathrm{MH}, \mathrm{Wu} \mathrm{MJ}$, Guo LP, Cao L, Wu HY, Zhang XN. Study of Fluorescence and CT Bimodal Imaging of Ultrasmall Gold Nanoclusters. Acta. Chim. Sinica. 2018; 76: 709-714.

99. Yang WT, Wu XL, Dou Y, Chang J, Xiang CY, Yu JN, Wang J, Wang XL, Zhang BB. A human endogenous protein exerts multi-role biomimetic chemistry in synthesis of paramagnetic gold nanostructures for tumor bimodal imaging. Biomaterials. 2018; 161: 256-269.

100. Li ZH, Ding H, Yan F, Li HW, Chen ZJ. Transformable protein-gold hybrid materials serve as supramolecular vehicles for gene delivery. RSC Adv. 2017; 7: 51252-51256.

101. Zhang LX, Li ZH, Jing JB, Ding H, Chen ZJ. DTT-Au NCs Interact with DNA to Form Raspberry-Like Particles. Part. Part. Syst. Charact. 2019; 36: 1800517.

102. Zhang XD, Luo ZT, Chen J, Shen X, Song SS, Sun YM, Fan SJ, Fan FY, Leong DT, Xie JP. Ultrasmall Au10-12(SG)10-12 Nanomolecules for High Tumor Specificity and Cancer Radiotherapy. Adv. Mater. 2014; 26: 4565-4568.

103. An DY, Su JG, Weber JK, Gao XY, Zhou RH, Li JY. A Peptide-Coated Gold Nanocluster Exhibits Unique Behavior in Protein Activity Inhibition. J. Am. Chem. Soc. 2015; 137: 8412-8418.

104. Lundqvist M, Stigler J, Elia G, Lynch I, Cedervall T, Dawson KA. Nanoparticle size and surface properties determine the protein corona with possible implications for biological impacts. Proc. Natl. Acad. Sci. USA. 2008; 105: $14265-14270$. 